\title{
The metaphysics of environmental responsibility in the context of self-determination of human being
}

\author{
Tatyana Torubarova ${ }^{1, *}$ and Olga Dyachenko ${ }^{1}$ \\ ${ }^{1}$ Kursk State University, 29 Radishcheva St., Kursk, 305000, Russia
}

\begin{abstract}
The article analyzes the metaphysical meaning of responsibility as a fundamental constituent of human existence. The urgency of the research is determined by contradictions of modern information-driven civilization, simulative nature of reality imitating human life, with man becoming the construct of rational schemes and technical manipulations, i. e. the conditions leading to downplaying human essence of a sane and responsible personality. The correlation of personality, freedom and responsibility in the metaphysical experience of man is revealed. It is shown that responsibility forms personal competence of man, is a structural element of his metaphysical experience, his event structure. The essence of responsibility as a structurally forming element of human existence, performing man-forming function, is analyzed. In this respect the problem of man's identity in the modern world is comprehended. The essence of freedom as the reverse side of responsibility, as responsibility for one's own content and being is shown. The notion of moral responsibility is explicated. The conclusion is made that the criterion of responsibility should be placed at the basis of human relations with the world.
\end{abstract}

\section{Introduction}

The reason for addressing the problem of responsibility is that this phenomenon in the horizon of metaphysical questioning leads us to comprehend the fundamental foundations of human existence, to the issues of man's rootedness in the world. At present the theme of freedom and responsibility is constantly attracting the attention of researchers from around the world. For example, scholars from Indonesia, Hedy Desiree Rumambi and Susy Amelia Marentek analyse the theme of corporate social responsibility and the related problem of human dignity [1], Lithuanian authors Jolanta Urbanovič and Loretta Tauginenie consider the ethical issues that are associated with the results of scientific research and their use, as well as the ratio of institutional and personal responsibility [2]; the Turkish researcher Nurten Gokalp focuses on the impact of philosophy education on forming moral responsibility which promotes human rights and freedoms implementation without harming society [3]. Ecaterina Croitor from Romania presents the interpretation of the ethical implications of the responsibility phenomenon in the concepts of postmodernism [4], and Kristine Kinena from

\footnotetext{
${ }^{*}$ Corresponding author: ttorubarova@,rambler.ru
} 
Latvia points out the insufficiency of understanding by modern man in his daily activities of his close connection with others, the importance of personal responsibility in the context of relationships with people and nature, on which the future existence of the world as a whole depends [5]. In Russia most researchers focus their attention on comprehending social responsibility and civil liability. The works of Wittenberg E.Y. [6], Semitko A.P. [7], Tsvyk A.V. [8], Tsybulevskaya O.I., Milusheva T.V. [9] are devoted to this issue. Often the problem of responsibility is presented in the scope of psychological research, such as in publications by Volkova E.V., Bashkatov S.A., Chernyshova L.V. [10], Molchanov S.V. [11]. It is also noteworthy that Russian researchers much more frequently consider the metaphysical context of ethical categories such as freedom, responsibility, as well as the problem of philosophy of action, a topic developed by Academician A.A. Guseynov in his work "Philosophy of Action as the First Philosophy. (Experience of Interpreting the Moral Philosophy of M.M. Bakhtin)" [12]. He continues to comprehend the ideas presented in this publication in his second work with the same title [13]. The metaphysical foundations of ethical categories are touched upon by Yungus G.A. [14] as well as Kirshbaum S.V. [15] and others.

Thus, the metaphysics of responsibility in the context of self-determination of human being has not been the subject of special consideration, while responsibility defines human essence and is the fundamental basis of its explication. The contradictions of the modern technogenic civilization testify to the lack of demand for the human resource itself in its principal structural components, which alone make possible the phenomenon of human existence and the world, corresponding to its essence and purpose. Responsibility is a principal structure which attests, in Kant's words, to man's noumenal nature, that is, to such his dimension that defines man not as a biological being belonging to the natural order, but as a rational, sane being capable of reproducing itself in its proper human hypostasis. Such reproduction is only effected by a ceaseless personal effort, explicated in the desire to be human, to experience within oneself the inner supernatural influence that allows one to preserve one's identity. The preservation of man's identity has become a fundamental problem in contemporary society. The information-driven technological civilization, by providing essentially limitless possibilities of human self-determination, places the criterion of responsibility at the core of his relationship with the world, as long as human survival and preservation are at stake. Under the conditions of the technogenic world, anthropocentric ambitions are increasingly revealing their paradoxical nature, which, on the one hand, consists in man's claim to unlimited self-assertion and self-fulfillment, to self-endowing of man with power and domination over all things, while, on the other hand, leads to the loss of the human principle itself. This actualizes and makes urgent the problem of metaphysical principles that are constitutive in human being itself, among which a special role belongs to responsibility.

The aim of the study is to explicate the metaphysical context of responsibility as a fundamental event of constituting human existence in the world, its essential nature.

\section{Materials and methods}

The methodological basis of this study is the method of ascent from the abstract to the concrete, allowing to expound the problem of the metaphysical foundations of human freedom. The methods of structural and functional analysis were used to comprehend responsibility in the context of self-determination of human being through the prism of modes of its existence. The principles of systemic approach were also used in studying the philosophical foundations of human being self-determination. The application of the dialectical method allowed to consider the peculiarities of life organization of man as a free 
personality and to reveal the understanding of self-restraint as awareness of the measure of personality's own responsibility.

\subsection{Relevance}

The problem of freedom is one of the most important horizons of philosophical thought, providing a key to comprehending that metaphysical position which has formed the basis of the modern worldview and world understanding. The experience of comprehending this theme is very problematic because it addresses a very broad spectrum of issues. Nowadays moral and psychological, legal, political and economic, social aspects and determinations in the horizon of this theme comprehension and explication are becoming more and more urgent. Moreover, the key trends of modern information-driven technological world define the leading plot lines, main approaches and semantic crystallizations of the general content of the problem field, in which modelling, construction and schematization become a formmaking principle. In this way, the problem of freedom is deprived of fundamental, metaphysical comprehension and philosophical understanding. This is why new approaches are needed to research its problematic context in its structural semantic units. And the most important such constitutive unit is responsibility.

Freedom in its metaphysical comprehension is inseparable from responsibility. The rejection of responsibility is nothing other than the rejection of freedom. Freedom is a condition of man's being, of the overcoming of his "I", restoring his inherent unity and integrity of being. The content of responsibility is proportional to the degree of man's rootedness in the world. Responsibility consists in such a dimension of human essence, in which man, by a relentless effort of affirmation, constitutes in himself the essence of being, the possibility of the growth of anything at all. This condition presupposes a personal dimension of man that implicates in itself a rational, individual and responsible bearer of this act, as a subject of free action. The act of freedom is fulfilled in responsibility and thus in conformity with everything one deals with, in the ability to be aware of the consequences of one's actions in the world. Responsibility forms personality, being the structural unit of its noumenal essence and is revealed in the unity of two aspects: firstly, as responsibility for one's own content and as moral responsibility, that is, responsibility for one's being.

\section{Discussion}

The metaphysics of morality expresses man's essential understanding of his decisions and actions. In this connection, one cannot but agree with A.V. Skomorokhov who, setting out to find out the reasons of "the rupture between metaphysics and ethics", notes that there is an "anti-metaphysical turn of modern philosophy" in modern thought [16, p. 125]. However, the researcher O.P. Zubets finds that "the identification of the metaphysical foundations of ethics" is, in my view, philosophically and ethically flawed as it inherently relegates ethics to the place of a deduced consequence" [17, p. 78]. Nevertheless, the metaphysics of morality cannot be eliminated from human spiritual experience, for it expresses a fundamental feature of man's comprehension of reality of his place and purpose in the world. This kind of metaphysics is revealed in M.M. Bakhtin's philosophy of action. It speaks about an acting action, as always a sane, i.e. a conscious and responsible, choice. This act is inimitably personal, filled with responsibility for one's being. The responsible and meaningful action is performed on the basis of the recognition of "the ought onliness", that is, "the oughtness in the unity of my only responsible life" [18, p. 75]. The action is always done here and now, it is a fundamentally personal act out of which the only life is composed as an act creating new realities. Personality and human existence are linked to a unique destiny in the integrity of the world around us, because they express a measure of the meaningful, responsible 
involvement of the individual in the world. It is such being of the human spirit that is capable of responding to every event in the being of the world. Personality is formed in the response, in the capacity to respond, and thus to correspond to everything that calls out to it, in one way or another. This is the experience that weaves the fabric of being as co-existence. The meaningfulness of being, its comprehension are dialogical in the sense that human being is being in the world, for it depends on the interaction and interconnection of the individual with others. The moment of such existence-coexistence is rooted in responsible human action. It is the responsible inclusion of my "I" as a participating doer in the onliness of existence-coexistence. I am personally involved in the event, for in this involvement my particular responsibility, my freedom, are fulfilled. Freedom is the freedom of responsibility, which is the measure of man's rationality as a sane being. Man as a rational and responsible being has no alibi in being. He is called upon to respond by engaging and participating in the world as the event basis of constituting man's being proper. The content of responsibility as the measurement unit of freedom correlates with the self-determination of man as a rational being.

We have an initial situation in which man, as it were, is suspended in the air, over a void. This situation is precisely related to the risk of effort made by oneself, moreover, made every minute. This is precisely the situation of freedom in the sense of responsibility, being doomed to freedom, of which J.P. Sartre says: "The essential consequence of our preceding remarks is that man, being condemned to freedom, bears the whole burden of the world on his shoulders; he is responsible for the world and for himself as a way of being". This idea is often quoted by contemporary researchers when addressing the problem of correlation of freedom and responsibility, such as P.E. Matveyev who, referring to the idea of J.P. Sartre, nevertheless, believes that freedom and responsibility can have different bases [18, p. 74]. The appeal to a person of sanity helps to see this fundamental situation characterizing the position of man in the world. This state is personal, implicating in itself a rational, individual and responsible bearer of this act.

Man's contemporary situation is defined by his vulnerability in being. To be himself, man must exist in the act of transcending, of constantly surpassing himself. More often than not, however, we do not burden ourselves with any effort, but are content, as Plato would say, with imaginary sustenance, remaining inhabitants of the realm of shadows. It is about a real catastrophe that we are experiencing. It is an anthropological catastrophe, a catastrophe connected with the rebirth of human consciousness, which has already acquired an instrumental character and closed itself off in the world of shadows. We are dealing with a sense of being or not being that is inseparable from the fulfillment of the act of thinking, which is reproduced in the wave of personal effort. Our competence of thought and action depends on it. Obviously, we experience the force that produces us where we deny ourselves, the force that allows us to endure, that gives us the courage to be. Tragic is the life that imitates life. Sometimes people's spiritual life is brought about by dead letters devoid of any meaning. It is thought that does not fulfill the laws of thought itself. And the laws of thought are inseparable from memory. Nowadays in the technogenic, information-driven civilization thought is exhausted, deprived of its intrinsic energetic beginning. That is why it is necessary for thought to turn to its own sources, which renews thought and gives it the necessary energy. This poetic aspect of thought (which always has a reversible nature) is eliminated by the very rhythm of the contemporary epoch. This is why there is a need for a "catharsis" that makes it possible to engender in us something that we cannot get naturally, that we would never come to by continuing our natural powers. And this requires a public space, that gap which is the condition of the birth of thought itself, the possibility of its emergence. Thought is not contained in the head of man, it is spatial, existing always in the space "between". The destruction of this space is the destruction of the inner sources of harmony, the inner possibilities of thought itself. Man is not all in man. We still have to come to ourselves. This 
is why we still need living acts, living states, possibilities having their own conditions of being. This is precisely what acts of responsibility testify to.

The problem of responsibility is one of the key problems associated with human selfdetermination, with the search for opportunities and conditions for personal fulfillment. It is responsibility that sets and forms the personal competence of man, his so-called personal backbone as the basis for the reproduction of human life. The personal dimension of human existence is provided by the topological structuredness of our metaphysical experience and is fixed by the procedure of deriving experience, which is crucial for determining the value of a human act and the ability to accomplish it. The structural element of man's metaphysical experience which constitutes his personal identity is his personal responsibility. Then we speak of freedom and responsibility which are not commensurate with the particular characteristics of the empirical man and are not commensurate to his being. Rather, what is meant is the foundations of man's being that have a metaphysical status and correspond to his noumenal nature. The vector of human existence is set by structural components that have no practical or pragmatic basis, but which have a decisive influence on ourselves. Such structures are essentially a formative principle, and encapsulate an infinite intensity.

This certainty is redundant in relation to us as beings belonging to the natural order of things. But thanks to these kinds of states, we exist by right of second birth, in the proper human qualities in which the human phenomenon is recreated. Here it is not a question of constructing my individuality or distinctness, but of the fundamental self-value and irreplaceability of man as a person, a personality always sane and responsible. It is man's way to himself, an inner imperative of his self-support. The modes of modern man's existence are expanding the boundaries not only of his self-determination, but are also making the boundaries of the human "I" movable. In a world dominated by information technologies, there is a new transcendental "I" boundaries expansion blurred into all kinds of positions, masks and social roles, and in fact leading to downplaying the phenomenon of personality which becomes a construct of rational schemes and technical manipulations. The key is the meaning of persona, which this notion embodied in antique metaphysics position, focusing on the meaning determinations corresponding to the social aspects of the idea of citizenship, but, much more importantly, related and belonging to characteristics of individuals themselves. In this kind of emphasis, the individual as persona is a countenance, a mask, in accordance with which, playing a certain role, he is the agent of a certain action in the overall matrix of the modern world's being. The constant change of models recognizable only in their naked "thisness" levels out the deepest sense of the eventful fulfillment of the phenomenon we call personality, the phenomenon that is as if embedded in our inner "I" as its structural, constitutive composition and allows us to understand ourselves in our "whatness", essential, human nature.

Responsibility is the key structural constituent of human being, the inner backbone of its personal self-determination. Human existence is not externally set, it cannot be deduced from the external assumptions of the natural world. The very status of human being presupposes a metaphysical experience of man's rootedness in his own foundational content where freedom, dignity, responsibility, honour form his topos, a topos in which man is able to come to himself, to find himself in his own nature called human being. What is meant here is the metaphysical constituents of our life, performing a man-forming function, the structural units of our being. One of the structure-building elements of human existence is responsibility. Responsibility is such a structural component, thanks to which we recognize and know ourselves as a free sane personality. We find the consequences of actions, included in these kinds of structures, in empirical reality. The constructive role of the responsibility phenomenon in human existence manifests itself not only in relation to the experience of constituting human existence as such, but also in relation to the empirical consequences of man's actions carried out in the element of responsibility. This means a form of man's 
crystallization, the constructive element as a symbol of the second birth. That is, in addition to real, ordinary, everyday life, there is another one that brings order to the human soul and transfers man into another mode of existence that is impossible for the natural human creature belonging to the natural order of all things existent. This other mode of existence, belonging to the very essence of man, requires constant attention, exertion and effort on his part, involvement in these ordered structures, which are a kind of matrices of human existence. Responsibility as a metaphysical element of the intrinsic human principle in our nature is held in place by the continuous exertion and intense effort of people and only in this way can it take place and be constitutive in relation to the kind of person it is. Freedom is not something once conquered in itself. Responsibility contains no terms referring us to empirical, observable states and phenomena, but is a constructive element which influences us in such a way that a free, sane, human personality is formed and born on the basis of it. What is meant here is a form that gives birth to us within itself, within which the human in man is produced. These kinds of elements tune our thinking. They set the limit within which human events exist. We as humans exist in a field shaped by these kinds of structures (structural components) that set the mode of our existence. There is an infinite reproduction effect in the re-creation of human nature. Man is a phenomenon that is paradoxical and at the same time borderline, combining in himself the finite physical world and the transcendent beginning of the infinite. It is a position which must be constantly reacquired and regained each time. One cannot acquire one's essence once and for all. Man is always a possibility of being man. Man is a being who is always in a state of becoming, and all history can be defined as the history of his effort to become man. Man, by virtue of the conditions of his existence, lives not only within the framework of our material world, but also in conditions that require an infinite dimension. In the human element itself, there are the kinds of structures that require the infinite, that is, the fulfillment by man of his purpose contained in our ontological design. It is a case of man's creation of himself in his proper human qualities which are not generated by natural processes. The human constitution itself is generated by such structural components, that is, we participate in this kind of organization by our own exertion, by our will. Responsibility is the way of organizing the life of man as a free personality. Responsibility is not to someone or something particular, but responsibility in this metaphysical sense, responsibility of my participating thinking, reproducing me fulfilling my purpose. The purpose of man is rooted in this responsibility, which is a free, independent, unique act of our ontological individuation (harmony). Human pathos is based on coexistence, on the reproduction of specific human actions. Responsible action fulfills human dignity, it is redundant in relation to natural, empirical processes and phenomena. One cannot be responsible half-way or conceptualize it as the sum of added units, making arguments characteristic of empirical reality phenomena. Responsibility presupposes metaphysical wholeness and my personal sanity. The act of free, personal, sane action presupposes all the totality of my responsibility. In this way the unified construction produces the human phenomenon, sets its specificity by the rules and laws imposed by the structure itself. Overcoming these rules leads to the destruction and emptying of the human being.

Freedom is the world working through us. And we notice the manifestations of its actions on us. It is not freedom of choice and not an object that can be possessed. On the contrary, "freedom is revealed to man first of all in choice and the unconditional possibility of man to exercise it" [19, p. 62]. Freedom is the world operating within us. In the ether of the metaphysical elements of this world we find its consequences as a possible horizon for the fulfillment of our acting actions. One of these metaphysical, constructive elements is responsibility, responsibility as the realm of our personal fulfillment and sane action. In this sense, freedom is understood as necessity. It is about a force at work in us which we cannot grasp objectively. But we grasp in us the action and the manifestation of freedom as an act of responsibility, the results of which take place in me. And we grasp this reflexively. 
Responsibility always presupposes the totality of the will, one cannot be responsible halfway. It is an act that always depends on me, on my determination, and is generated by me.

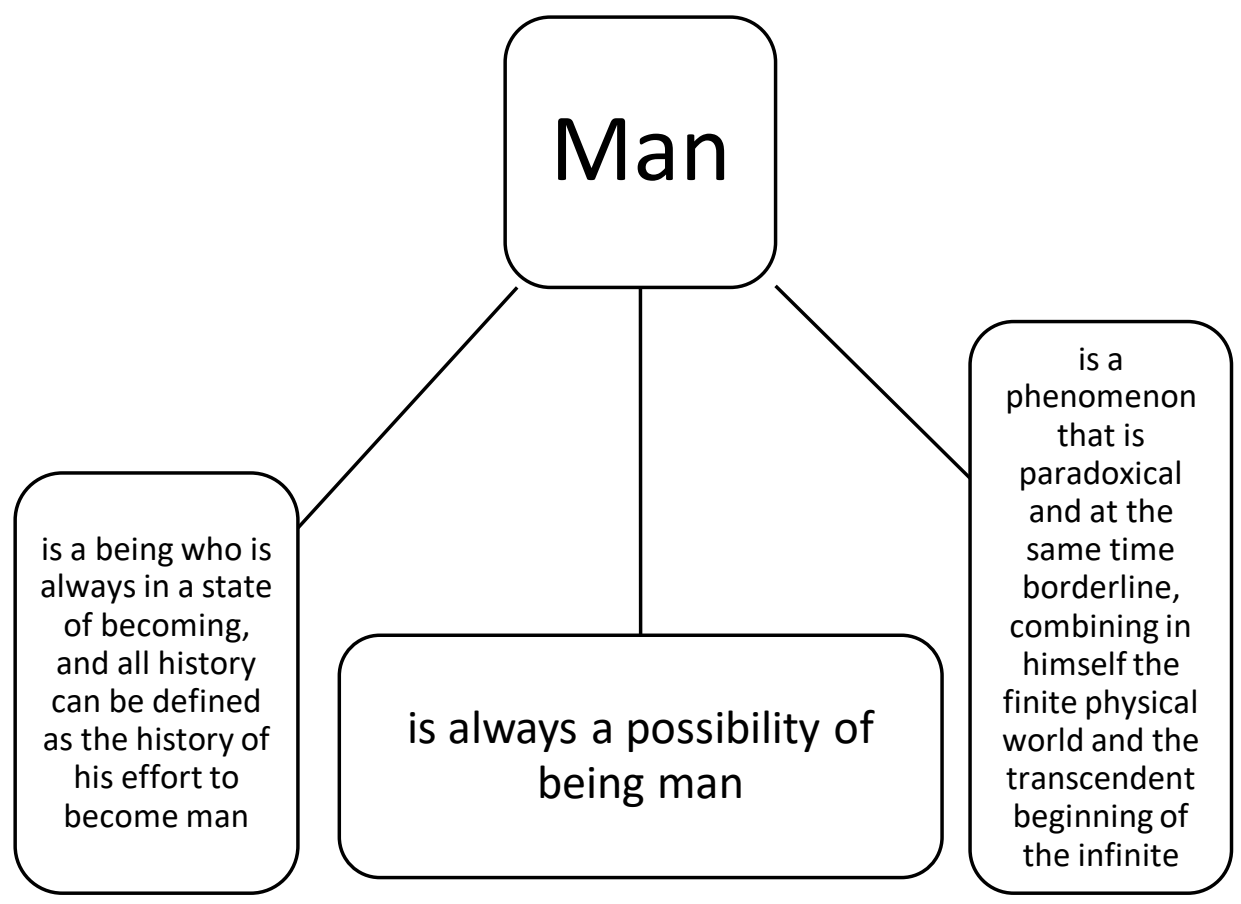

Fig. 1. Man in the space of responsibility.
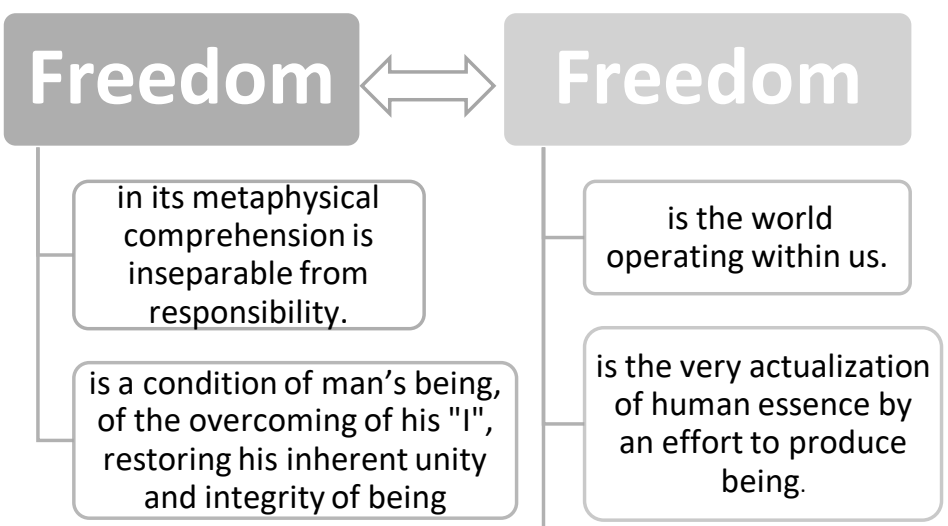

Wholeness and meaning are always connected to the awareness that greater freedom entails greater responsibility

Fig. 2. Freedom and responsibility. 
Thus the human personality, knowing itself to be responsible, is the structural formation on the basis of which stable human qualities are crystallized and reproduced, from which experience is derived. Turning to oneself, striving to make sense of oneself, is initial and the necessary procedure for extracting experience. This procedure implies personal responsibility of man for the here and now, the courage to be, to be in the effort, strained to the limit and each time anew. It is a continuous state, allowing man to fulfill his purpose each time in a unique way. Responsibility does not depend on a series of causes that we establish or on consequences that take place in our empirical experience, but requires wholeness, completeness and completion. It is an event belonging to our metaphysical experience as an element of its co-existence structure. It is an integral form recreating man as a free personality. What is meant here is personal-being acts where the foundations of human being are produced. These are such kinds of formations in the horizon of which our personal experience as free beings is fulfilled. These formations are constructive in relation to us, producing in us those states that do not occur naturally and causally. They produce us by imposing on us a personal sanity through which his proper human qualities are born and reproduced in man, allowing us to speak of his self-identity.

\section{Results}

Responsibility accumulates always the inner, personal pathos and the content of free spirit. The acceptance of one's responsibility constitutes the dignity of the human personality capable of being sane and rational in its actions. Rationality presupposes the self-limitation of personality as awareness of the measure of its own responsibility. This measure determines the mode of being of the human in man, and is his self-identification value. Freedom is the very actualization of human essence by an effort to produce being. The condition of constituting of such an essence is its reproduction through metaphysical structural elements, one of which is responsibility. It is in responsibility that the unity of inner and outer reality, overcoming the extremes of individualism and collectivism, overcoming the decay of the human personality, are fulfilled. The position of modern man in the world resembles more an escape from himself. In striving to fulfill his anthropocentric ambitions, he distances himself more and more from himself, in fact, no longer recognizing in anything his true nature, which means that man's relationship to anything is deprived of the constitutive basis by which only he can be human. That is why it is important nowadays to learn to be human, recognizing oneself in the connections and relations we establish, deriving experience in experiencing the fulfillment of the metaphysical structural units (honour, responsibility, conscience, personality) that channel and safeguard the true human nature.

Not only is the human essence in its rational, responsible nature dispersed today, but the world is no longer the "native home" of human presence. The commensurability of man and the world is only possible where there is a sane, personal being capable of responsibility on the wave of its own effort, of "fear and trembling", filling the emptiness and nothingness that we leave behind us and in which we are always involved. Wholeness and meaning are always connected to the awareness that greater freedom entails greater responsibility. This proportionality sets possible content and measure of responsibility, testifying to the degree of responsibility for everything that is revealed to us in one way or another on the level of human decisions and actions above all. It is the metaphysics of responsibility that expresses the fundamental way in which man conceptualizes the world and his place and purpose in this world. 


\section{Responsibility}

is the key structural constituent of human being, the inner backbone of its personal selfdetermination

The acceptance of one's responsibility constitutes the dignity of the human personality capable of being sane and rational in its actions. presupposes the selflimitation of personality as awareness of the measure of its own responsibility

It is an act that always depends on me, on my determination, and is generated by me presupposes the totality of the will, one cannot be responsible half-way

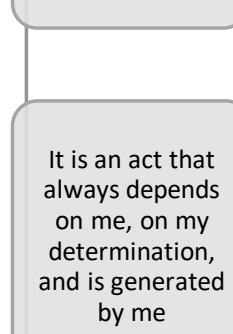

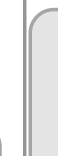

is such a structural component, thanks to which we recognize and know ourselves as a free sane personality. contains no terms referring us to empirical, observable states and phenomena, but is a constructive element which influences us in such a way that a free, sane, human personality is formed and born on the basis of it.

Fig. 3. Responsibility in personal self-determination.

\section{References}

1. H.D. Rumambi, S.A. Marentek, A Human Dignity Perspective: Exploring The Implementation of Corporate Social Responsibility, Procedia - Social and Behavioral Sciences 211, 127-134 (2015) https://doi.org/10.1016/j.sbspro.2015.11.019

2. J. Urbanovič, L. Tauginienè, Institutional Responsibility vs Individual Responsibility: Ethical Issues in the Management of Research Performance, Procedia - Social and Behavioral Sciences 81, $72-78$ (2013) https://doi.org/10.1016/j.sbspro.2013.06.390

3. N. Gokalp, Philosophy Education and Human Freedom, Procedia - Social and Behavioral Sciences 47, 477-479 (2012) https://doi.org/10.1016/j.sbspro.2012.06.683

4. E. Croitor, Ethics of Responsibility? Some Postmodern Views, Procedia - Social and Behavioral Sciences 149, 253-260 (2014) https://doi.org/10.1016/j.sbspro.2014.08.226 
5. K. Kinena, Responsibility as a Condition for Meaningful Action, Procedia - Social and Behavioral Sciences 116, 4375-4378 (2014) https://doi.org/10.1016/j.sbspro.2014.01.950

6. E.Y. Wittenberg, Social responsibility of civil society: debatable issues of theory (Part 1), Sociological Science and Social practice 2 (18), 63-76 (2017) DOI: 10.19181/snsp.2017.5.2.5150

7. A.P. Semitko, On the priority of human rights and freedoms as a legal principle of liberalism in Russian and foreign literature, Scientific annual book of Institute of Philosophy and Law of Ural branch of Russian Academy of Sciences 17, 1, 83-105 (2017) DOI: 10.17506/ryipl.2016.17.1.83105

8. A.V. Tsvyk, Ethics of political responsibility in international relation, Bulletin of RUDN, Series: International Relations 17, 2, 257-264 (2017) DOI: 10.22363/23130660-2017-17-2-257-264

9. O.I. Tsybulevskaya, T.V. Milusheva, Freedom and personality dignity: philosophical and legal aspects, Bulletin of the Nizhny Novgorod Academy of the Ministry of Internal Affairs of Russia 2 (46) (2019) DOI: $\underline{\text { 10.24411/2078-5356-2019-10209 }}$

10. E.V. Volkova, S.A. Bashkatov, L.V. Chernyshova, Review of research on responsibility in domestic and foreign philosophy of the XXI century, Pedagogy. Psychology. Sociokinetics 4, 53-59 (2019) DOI 10.34216/2073-1426-2019-25-4-53-59

11. S.V. Molchanov, Moral self-justification as the myth of "moral freedom" of the personality, National Psychological Journal 3 (35), 60-70 (2019) DOI: $10.11621 / \mathrm{npj} .2019 .0307$

12. A.A. Guseynov, The philosophy of action as the first philosophy. (Experience of interpreting the moral philosophy of M.M. Bakhtin) Article one: To be is to act, Questions of Philosophy Journal. Moscow, Institute of Philosophy of Russian Academy of Sciences 6, 5-15 (2017) DOI: 10.31857

13. A.A. Guseynov, The philosophy of action as the first philosophy. (Experience of interpreting the moral philosophy of M.M. Bakhtin) Article two: The first philosophy as moral philosophy, Questions of Philosophy Journal. Moscow, Institute of Philosophy of Russian Academy of Sciences 7, 65-74 (2017) DOI: 10.31857

14. G.A. Yungus, Philosophical understanding of the conclusion of an agreement out of court as a responsible action through the moral philosophy of M.M. Bakhtin, Ideas and Ideals 11, 1, 1, 86-102 (2019) DOI: 10.17212/2075-0862-2019-11.1.1-86-102

15. S.V. Kirshbaum, On the boundaries of freedom, Ethical Thought 17, 1, 70-79 (2017) DOI: 10.21146/2074-4870-2017-17-1-70-79

16. A.V. Skomorokhov, Metaphysics as the basis of moral philosophy: state and possibilities, Ethical Thought 18, 1, 124-129 (2018) DOI: 10.21146/2074-4870-201818-1-124-129

17. O.P. Zubets, Non-metaphysical foundations of ethics, but ethics as the first philosophy, Ethical Thought 18, 1, 78-83 (2018) DOI: https://doi.org/10.21146/2074-4870-2018$\underline{18-1-78-83}$

18. P.E. Matveyev, Philosophy of action by M.M. Bakhtin (experience of ethical interpretation), Ethical Thought 16, 2, 70-83 (2016) DOI: 10.21146/2074-4870-201616-2-70-83

19. R.G. Apersyan, Freedom: experiences of comprehension and experiencing, Ethical Thought 17, 1, 56-69 (2017) DOI: 10.21146/2074-4870-2017-17-1-56-69 